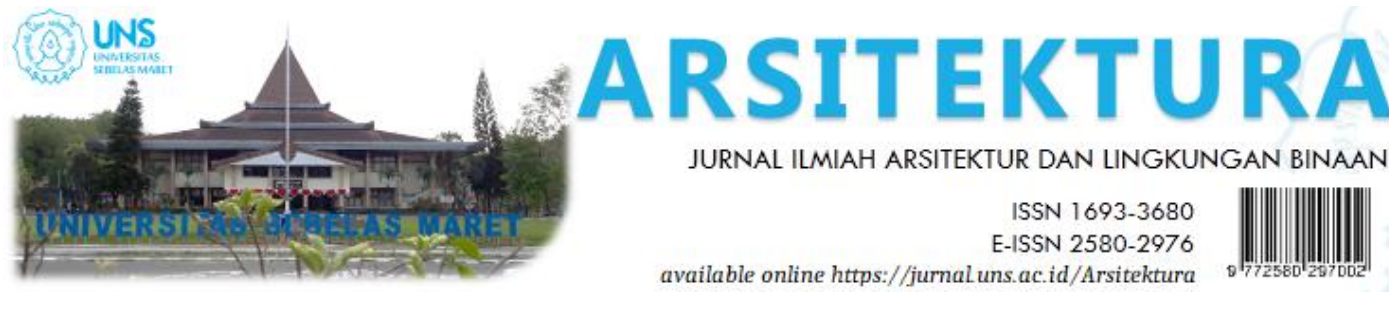

Volume 19 Issue 1 April 2021, pages:51-62

\title{
Akulturasi Islam dan Budaya Jawa pada Ruang Liwan Masjid Gedhe Mataram Kotagede
}

\section{Islamic And Javanese Culture's Acculturation in The Liwan Room Of 'Gedhe Mataram'Mosque Kotagede}

\author{
Pradianti Lexa Savitri ${ }^{1}$, B. Sumardiyanto ${ }^{2}$ \\ Mahasiswa Program Studi Magister Arsitektur Universitas Atma Jaya Yogyakarta ${ }^{1)}$ \\ Coresponding Author:b.sumardiyanto@uajy .ac.id \\ Dosen Pembimbing Program Studi Magister Arsitektur Universitas Atma Jaya Yogyakarta ${ }^{2)}$
}

DOI: https://doi.org/10.20961/arst.v19i1.45153

Received: October 23,2020 Revised: February 10,2021 Accepted: February 15,2021 Available online: April 30,2021

\begin{abstract}
This article aims to demonstrate the acculturation of Islam and Javanese culture in the Liwan Room of "Gedhe Mataram" Mosque, Kotagede. Islamic and Javanese culture's acculturation in the building, especiallymosque, important known to add insight about the tolerance between two cultural elements that can occur in the architecture's world. Liwan room is part of the space of a mosque which functions as a prayer area. Liwan Room at the "Gedhe Mataram" Mosque, Kotagede has a distinctive design considering this mosque is the first and oldest mosque in Yogyakarta. The development of Islam in Java, especially in Yogyakarta, resulted in the transformation of local civilizations. Islam and Javanese culture itself are two different elements and have their own value. The entry of Islamic culture to Java had an impact on the acculturation of Islam and Javanese culture, where Javanese culture had already lived during the time of the Javanese Hindu kingdoms. The method used is a qualitative research method with a philosophical approach supported by observation and library studies. As a result, there is an acculturation of Islam and Javanese culture in the Liwan Room of "Gedhe Mataram" Mosque, Kotagede in layout, interior elements and ornaments in the Liwan room.
\end{abstract}

Keywords: acculturation, Islam, Javanese Culture, mosque

\section{PENDAHULUAN}

Kebudayaan menjadi bagian dari denyut nadi sebuah masyarakat dalam satu wilayah. Kebudayaan meliputi agama, sistem sosial, ekonomi, politik, seni, arsitektur, dan lain sebagainya. Kebudayaan memiliki nilai penting yang menjelaskan mengenai konsep kehidupan masyarakatnya. Menurut Koentjaraningrat (2009, hlm. 67) kebudayaan daerah bisa diartikan merupakan sebuah konsep suku bangsa yang tak lepas dari sebuah pola aktivitas masyarakat serta dipengaruhi oleh faktor geografis.

Faktor geografis ini akan menentukan bagaimana kebudayaan lain dapat masuk dan menyesuaikan diri dengan pola kehidupan yang telah dijalani oleh masyarakat setempat. Masuknya kebudayaan dari luar tersebut 
memungkinkan terjadinya suatu akulturasi nilai budaya, contohnya seperti pada saat kebudayaan Islam masuk untuk pertama kalinya di Jawa. Saat itu masyarakat Jawa sendiri telah memiliki budaya lokal yang beraneka ragam, sehingga ketika Islam masuk tidak serta merta menggeser kebudayaan tersebut.

Transformasi kebudayaan berupa akulturasi antara Islam dan budaya Jawa diakibatkan oleh muncul dan berkembangnya Islam di Jawa yang memberikan dampak pada peradaban lokal yang telah mengakar dan berkembang pada masa kejayaan Kerajaan Hindu-Budha. Akulturasi tersebut terjadi pada segi arsitektur, seni, dan berbagai tradisi dalam kehidupan sehari-hari terutama dalam perayaan hari besar agama Islam.

Akulturasi merupakan sebuah proses dimana sebuah kelompok individu dengan kelompok individu lain yang memiliki budaya yang berbeda saling bersinggungan dan berinteraksi secara langsung sehingga terjadi perubahan terhadap pola dari budaya yang yang satu ke yang lain atau bisa terjadi dalam dua arah. Dalam salah satu tulisannya M.M Gordon terdapat tujuh variabel yang harus dikaji dalam proses asimilasi dimana salah satunya adalah Asimilasi budaya atau perilaku atau lebih dikenal dengan sebutan akulturasi dimana terdapat penyesuaian-penyesuaian yang terjadi pada pola kebudayaan terhadap kelompok yang lebih dominan. Proses akulturasi ini membuat dua budaya yang bersinggungan tersebut dapat menerima masing-masing nilai yang dibawanya. Proses dalam akulturasi dapat berhasil jika terdapat sebuah penerimaan tanpa rasa terkejut sebagai wujud sebuah persenyawaan (affinity). Persenyawaan ini dapat diibaratkan sebagai sebuah 'penyerap' menurut Gillin atau sebuah penjiwaan menurut Amman. Dari hal tersebut dapat ditarik kesimpulan bahwa akulturasi memiliki ciri utama dimana terdapat penerimaan kebudayaan asing yang diolah ke dalam kebudayaan lokal tanpa menghilangkan identitas asal (Roszi, 2018).

Sistem kekuasaan dalam pandangan Jawa memiliki konsepsi kesakralan dalam bentuk wahyu (dewa/raja) dimana seluruh instrumen pendukungnya tunduk pada suatu sistem hierarkis yang sakral yaitu energi Ilahi yang meresapi seluruh kosmos dan bukanlah hasil relasi individu dengan individu lain ataupun kelompok (Kresna, 2013). Masyarakat Jawa juga lekat dengan kepercayaan yang penuh mitologisasi, sakralisasi, dan mistifikasi, dimana mitos bagi masyarakat Jawa merupakan orientasi spiritual dan mental untuk berhubungan dengan Tuhan (Fitri, 2012). Filosofi budaya pada masyarakat Jawa merujuk pada adanya jagad gedhe (alam besar) dan jagad cilik (alam kecil) dimana manusia yang dianggap sebagai bagian dari mikrokosmos harus dapat hidup berdampingan dengan alam sebagai makrokosmos. Hubungan yang harmonis secara vertikal ini juga memunculkan pandangan mengenai alam suci sebagai sumber pemberi kehidupan (Cahyandari, 2012). Pandangan kosmologi masyarakat Jawa dianggap sebagai komponen sakral dimana akhirnya melahirkan pandangan mengenai sumbu sakral berupa sumbu Utara-Selatan, gunung-laut, serta timur-barat dikarenakan terpengaruh budaya Majapahit (Santoso, Setioko, \& Pendelaki, 2015). Dalam kosmologi Jawa, kerajaan juga dianggap sebagai pusat 'dunia' yang dipimpin oleh seorang raja yang diidentifikasikan sebagai pusat alam semesta (yang harus dijaga) dimana dalam tradisi Hindu-Budha raja dianggap perwujudan dewa, atau secara Islami dianggap memiliki kebajikan yang diwakili oleh para dewa tersebut (Behrend, 1989).

Islam datang di Jawa pada masa pemerintahan kerajaan Hindu-Budha melalui para pedagang yang terdiri dari para imigran yang membawa Islam melalui proses dialektika (Muqoyyidin, 2012). Masa transisi religi dari Hindu-Budha ke Islam terjadi di tandai dengan munculnya kerajaan Islam di Indonesia. Kerajaan Majapahit sebagai kerajaan Hindu paling besar digantikan oleh Kerajaan Demak yang muncul sekitar pertengahan akhir abad ke-15 dan memiliki corak Islam (Ngationo, 2018). Pada masa transisi tersebut, penggunaan simbolsimbol Hindu pada sebuah karya arsitektur masih digunakan dikarenakan perubahan dengan masuknya corak Islam tidak terjadi dengan mudah. Gaya arsitektur Islam seperti masjid yang dominan memiliki gaya arsitektur Timur Tengah tidak dibawa melainkan bertransformasi menggunakan bentuk-bentuk 
lokal. Karakteristik budaya pada material yang dihasilkan seperti bangunan maupun data artefaktual merupakan salah satu aspek yang dapat digunakan untuk meninjau bentuk akomodatif Islam dengan budaya lokal (Handoko, 2014). Hal inilah yang menyebabkan bentuk dan corak bangunan Hindu-Budha masih tampak pada bangunan arsitektur masjid dan makam, seperti pada bagian atap, gapura, dan ornamen berupa simbol-simbol.

Penyebaran Islam oleh Walisongo di Jawa menggunakan pendekatan tasawuf (mistik Islam) dan dilakukan bertahap tanpa adanya penolakan terhadap kebudayaan lokal. Disinilah Islam menunjukkan adanya toleransi dan persamaan derajat pada saat pandangan dalam masyarakat Hindu-Budha memiliki penekanan terhadap perbedaan derajat. Hal ini kemudian menjadi daya tarik terutama bagi kalangan pedagang Islam dengan orientasi kosmopolitan yang mendapat panggilan untuk mengambil kekuasaan politik dari tangan penguasa (Majapahit).

Aspek struktur hingga setting perencanaan sosial politik pada bangunan masjid di Jawa didominasi oleh tradisi Jawa. Hal ini merujuk pada pernyataan seorang peneliti bernama Wustol Basri (2010) yang menyatakan bahwa bangunan masjid di area Keraton lebih menitikberatkan pada kultur Jawa bukan kultur Arab (Maryono, 2016). Kentalnya pengaruh budaya Jawa yang terlihat pada variasi arsitektur bangunan masjid merupakan perwujudan dari akulturasi Islam dan budaya Jawa (Aziz, 2013).

Akulturasi Islam dan budaya Jawa tercermin pada masjid-masjid di Jawa, seperti pada Masjid Gedhe Mataram Kotagede di Yogyakarta. Pendirian masjid ini ditujukan agar menjadi sebuah pusat penyebaran agama Islam atau menjadi sarana dakwah Islam. Kotagede merupakan bagian dari Kerajaan Mataram yang bernafaskan Hindu-Budha. Namun seiring berjalannya waktu, masyarakat setempat mulai bergeser memeluk agama Islam.

Masjid Gedhe Mataram Kotagede menjadi awal pusat penyebaran Islam di tengah-tengah pusat Kerajaan Mataram Hindu. Masjid Gedhe Mataram Kotagede merupakan peninggalan budaya yang sarat dengan sejarah karena menjadi masjid utama kerajaan dan menjadi salah satu elemen pokok dari konsep Catur Gatra Tunggal pada masa Keraton Mataram Islam. Konsep ini juga sering disebut dengan Civic Center dimana kota menjadi pusat berbagai kegiatan masyarakat, memiliki 4 bangunan dan poin pokok yang menggambarkan aspek-aspek pendukung dalam suatu kota yaitu keraton sendiri sebagai tempat tinggal raja, pasar sebagai pusat perekonomian, alun-alun sebagai ruang publik dan masjid sebagai tempat beribadah. Hal tersebut serupa dengan konsep yang dikemukakan oleh Selo Soemardjan mengenai konsep tata ruang negara Jawa Mataram berbentuk suatu sistem lingkaran dengan empat radius berbeda yang disusun hierarkis dimana pada radius pertama terdapat pagar-keliling (benteng) yang di dalamnya terdiri dari Keraton, beserta bangunan penunjang seperti alun-alun dan masjid (Soemardjan, 1962).

Masjid Gedhe Mataram Kotagede terletak di Kelurahan Jagalan, Kecamatan Banguntapan Bantul, tepatnya di selatan Pasar Kotagede. Masjid ini diperkirakan berdiri pada 1587-1601 oleh Panembahan Senopati Sutowijaya (Gambar 1). Posisi komplek masjid dan makam terletak di sebelah barat alun-alun dan dibatasi oleh jalan membujur ke utara-selatan. Masjid dan makam tersebut seluruhnya adalah bagian dari komplek Pasareyan atau makam bagi keluarga raja Mataram (Suratno, 2003). 


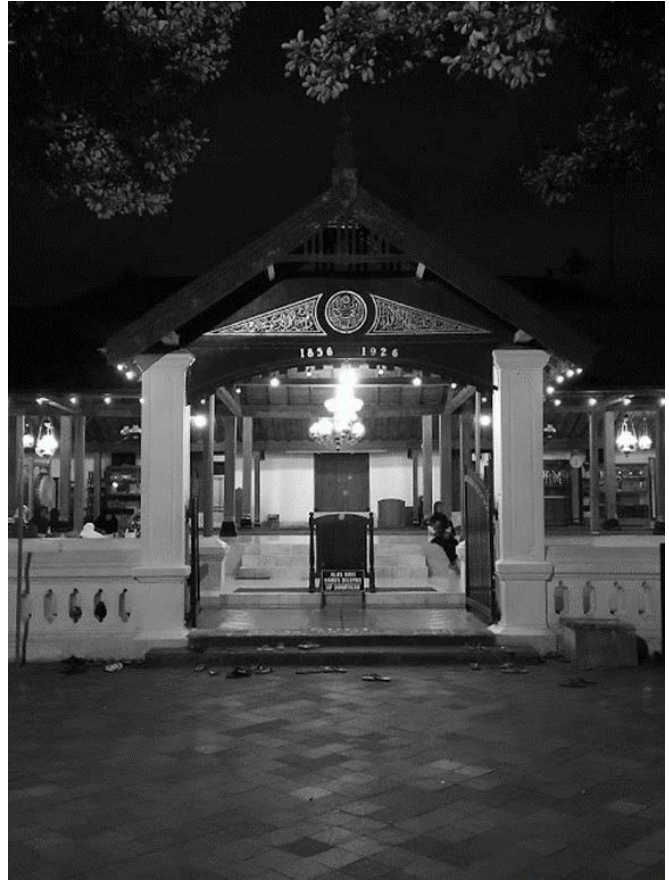

Gambar 1. Bangunan Masjid Gedhe Mataram Kota gede Yogyakarta Sumber:

https://www.chandranurohman.id/2017/06/masjidgedhe-mataram-kotagede.html, diunduh pada 24 April 2020,09:29

Fenomena perbedaan interior beserta elemenelemen arsitektur terlihat pada Ruang Liwan Masjid Gedhe Mataram Kotagede apabila dibandingkan dengan masjid lain pada umumnya yang bercorak khas Timur Tengah. Ruang Liwan pada masjid umumnya hanya berupa satu ruangan luas yang digunakan untuk sholat, tanpa kolom penopang di tengah (Saka Guru) seperti pada Ruang Liwan Masjid Gedhe Mataram Kotagede dikarenakan atap yang digunakan masjid pada umumnya berbentuk kubah (Gambar 2 dan Gambar 3). Selain itu masjid pada umumnya akan terlihat lebih modern dengan elemen-elemen struktur seperti beton, serta warna-warna yang lebih cerah, bukan warna alamiah seperti kayu. Ornamen yang terlihat juga hanya berupa Lafadz Allah SWT dan Nabi Muhammad SAW beserta kaligrafi dengan huruf Arab. Hal ini berbeda dengan Ruang Liwan Masjid Gedhe Mataram Kotagede yang memiliki ornamen khas Jawa di setiap bagian ruangnya.

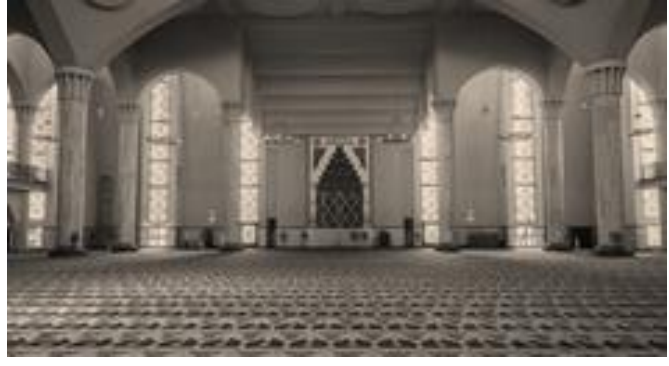

Gambar 2. Ruang Liwan pada Masjid Umum Bercorak Timur Tengah Sumber:

https://www.kontraktorkubahmasjid.com/arsitektur -islam-bagian-dari-sebuah-bangunan-masjid/, diunduh pada 25 Mei 2020, 09:29

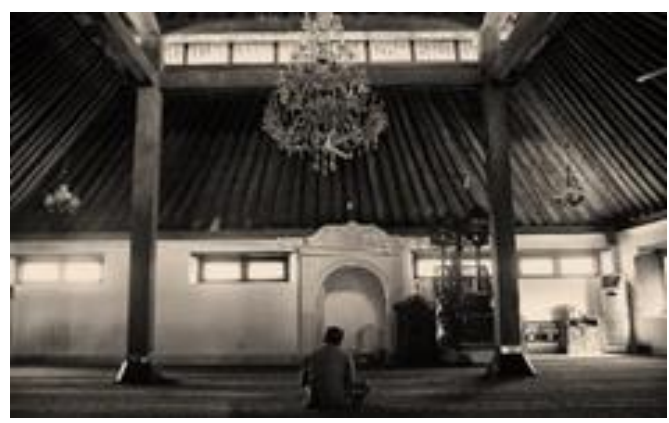

Gambar 3. Ruang Liwan pada Masjid Gedhe Mataram Kotagede

Sumber: https://www.gudeg.net/read/13202/masjidgedhe-mataram-kotagede-cikal-bakal-y ogyakartadan-penyebaran-islam.html, diunduh pada $25 \mathrm{Mei}$ 2020,09:00

Unsur-unsur arsitektur pada bentuk maupun ornamen yang terlihat berbeda pada Ruang Liwan Masjid Gedhe Mataram Kotagede tersebut merupakan bentuk toleransi antara umat beragama pada saat itu. Hal inilah yang melatar-belakangi penulisan karya ilmiah yaitu untuk menggali kembali khazanah arsitektural masjid-masjid yang mempunyai identitas Jawa seperti Masjid Agung Demak yang menjadi acuan masjid-masjid Kerajaan Mataram Islam, sehingga dapat ditelusuri lebih jauh dan menjadi latar belakang masalah di dalam tulisan ini yaitu bagaimana akulturasi Islam dan budaya Jawa tercermin pada Ruang Liwan Masjid Gedhe Mataram Kotagede. Objek yang akan dikaji adalah Ruang Liwan Masjid Gedhe Mataram Kotagede Yogyakarta yang merupakan masjid kerajaan Islam Mataram yang memiliki karakteristik identitas dari masyarakat Jawa. 
Permasalahan yang diangkat dalam tulisan ini berlatar belakang pada akulturasi Islam dan Budaya Jawa yang terwujud pada arsitektur bangunan di dalam Ruang Liwan Masjid Gedhe Mataram Kotagede di Yogyakarta. Ekspresi arsitektur Ruang Liwan pada Masjid Gedhe Mataram Kotagede yang tampak berbeda dengan pada masjid yang lain mendorong peneliti untuk melakukan penelitian lebih lanjut, mengingat masjid ini dibangun pada masa masuknya agama Islam di tengah masyarakat dalam Kerajaan Hindu-Budha. Tujuan penelitian adalah menunjukkan akulturasi Islam dan Budaya Jawa pada elemenelemen arsitektural Ruang Liwan Masjid Gedhe Mataram Kotagede di Yogyakarta. Pemahaman nilai terkait akulturasi Islam dan Budaya Jawa pada bangunan terutama masjid penting diketahui untuk menambah wawasan mengenai toleransi antar 2 (dua) unsur budaya yang dapat terjadi dalam dunia arsitektur.

\section{METODE}

Metode penelitian yang digunakan adalah metode penelitian kualitatif. Lokasi penelitian ada di kompleks Masjid Gedhe Mataram Kotagede di Yogyakarta. Pendekatan yang dilakukan mengacu pada objek studi yaitu Ruang Liwan pada Masjid Gedhe Mataram Kotagede yang memiliki elemen-elemen arsitektur yang juga merupakan ekspresi bentuk akulturasi dan menjadi objek yang sangat menarik untuk diteliti lebih lanjut.

Pengumpulan data dilakukan dengan cara pengamatan langsung ke lokasi untuk mendapatkan data yang terdiri dari data fisik berupa kondisi bangunan mencakup detaildetail arsitektur, struktur, komposisi warna dan ornamen. Kemudian dilakukan wawancara untuk mendapatkan informasi penguat dari data fisik dan pengamatan langsung. Selain itu ada pula data sekunder berupa kajian teori atau pustaka dari jurnal dan tulisan ilmiah terkait dengan Masjid Gedhe Mataram Kotagede.

Analisa dilakukan dengan membandingkan atau membaca dan menerjemahkan data-data yang ditemukan di lapangan menggunakan kajian teori atau pustaka yang telah didapatkan sebelum ke lapangan.

\section{HASIL DAN PEMBAHASAN}

\subsection{Makna Ruang Liwan Pada Masjid}

Unsur fisik masjid umumnya terdiri dari orientasi bangunan, bentuk, zona, bentuk atap, serambi, ruang Shalat, Mihrab, Material dan Warna, dan Mezanin (Utami, Thonthowi, Wahyuni, \& Nulhakim, 2013). Unsur-unsur tersebut juga terdapat pada masjid-masjid Jawa pada masa Kerajaan Mataram Islam, salah satunya yaitu pada Masjid Agung Demak yang dianggap sebagai tipikal masjid tradisional Jawa serta memiliki identitas universal. Masjid Agung Demak memiliki unsur khas seperti penggunaan material kayu, bentuk atap tumpeng dan Memolo (hiasan dari puncak atap yang diadaptasikan dari tradisi Hindu), terdapat tempat wudlu, serambi/pendopo, pawestren (ruang shalat perempuan), pagar/gerbang dan juga makam (Kusyanto, 2020). Unsur fisik masjid tersebut membentuk tipologi umum sebuah masjid. Keberadaan ruang sholat dan mihrab menjadi satu hal yang wajib ada di dalam sebuah bangunan masjid. Ruang Sholat memiliki istilah lain terutama pada masjidmasjid Jawa di Nusantara yaitu Ruang Liwan.

Ruang Liwan pada sebuah masjid adalah ruang tengah utama yang dipergunakan untuk sholat atau beribadah seperti membaca Al Qur'an juga I'tikaf yang memiliki makna sakral (Gambar 4).

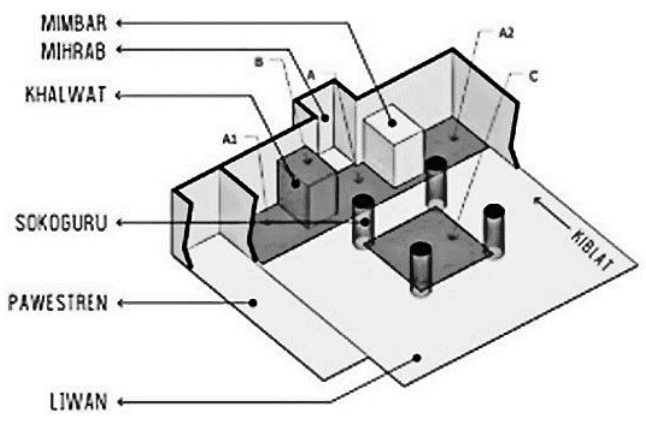

Gambar 4. Ruang Liwan Pada Masjid Jawa Sumber:https://www.njogja.co.id/bantul/masjidkotagede-yogyakarta/, diunduh pada 24 April 2020, $08: 34$

Ruang Liwan pada Masjid Gedhe Mataram Kotagede memiliki pola yang sama dengan masjid-masjid Jawa yang lain, yaitu memiliki mihrab, mimbar maupun Saka Guru. Ruang 
Liwan Masjid Gedhe Mataram Kotagede terletak di sebelah dalam dari area serambi masjid (Gambar 5).

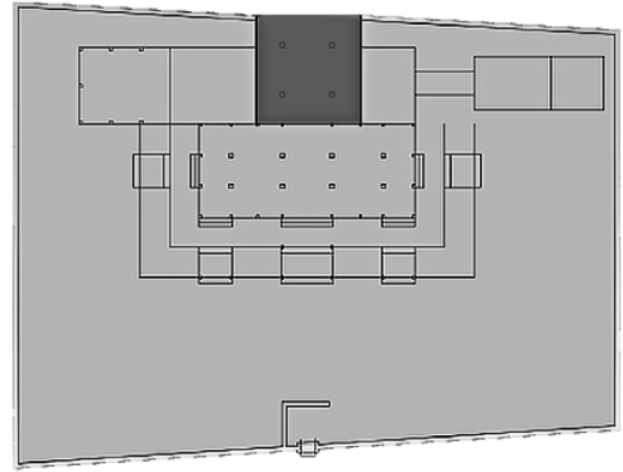

Gambar 5. Letak Ruang Liwan pada Denah Masjid Gedhe Mataram Kotagede

\subsection{Mencari Kebenaran Tentang Akulturasi Islam dan Budaya Jawa pada Ruang Liwan Masjid Gedhe Mataram Kotagede}

Rumusan atau inti dari sebuah karya arsitektur Islam bukan dilihat dari perwujudan bentuk fisik bangunannya, melainkan pada makna atau nilai hakiki yang terkandung di dalamnya. Konsep arsitektur Islam merujuk pada ayat-ayat yang berasal dari Al-Quran dan bentuk hukum alam. Di sini arsitek diharapkan mampu memenuhi The Law of God dan 'The Law of Nature', dimana rancangannya tidak bersifat merusak alam atau lingkungan sekitar serta harus sesuai dengan kebutuhan (Akromusyuhada, 2019).

Sejalan dengan kebudayaan Jawa dimana setiap tingkah laku maupun tindakan masyarakat Jawa selalu diwujudkan dalam bentuk simbolsimbol. Simbol dalam masyarakat Jawa tidak terbatas pada tingkah laku saja, akan tetapi juga dimanifestasikan dalam bentuk bangunan. Simbol-simbol di dalam penataan interior bangunan tradisional Jawa tercermin dalam pembuatan lantai yang dibuat bersusun yang dapat diartikan bahwa tempat tersebut memiliki derajat yang lebih tinggi dibanding dengan ruang lainnya. Nilai Islam dan Budaya Jawa yang berjalan berdampingan berdasarkan konsep kosmologi juga tercermin dalam Masjid Gedhe Mataram Kotagede.

Penentuan arah masjid terkait perletakan Mihrab di dalam Ruang Liwan sebagai arah sholat sesuai dengan kaidah ajaran Islam yaitu ke arah Barat berdasarkan letak Kiblat terhadap Indonesia (Gambar 6). Namun, letak Ruang Liwan Masjid Gedhe Mataram Kotagede terhadap ruang lain memiliki pola tatanan ruang pada yang sama pada masjid di Jawa yaitu memiliki kesamaan dengan tatanan rumah tradisional Joglo (Gambar 7). Unit melintang segi empat panjang (serambi) yang terletak di depan berdekatan dengan ruang sembahyang utama identik dengan pendopo pada rumah joglo. Dari serambi masuk ke dalam ruang sembahyang utama terdapat tiga pintu seperti tipe rumah Joglo untuk masuk ke bagian dalam atau disebut dengan dalem. Pada rumah tradisional terdapat ruang gandhok pada bagian sebelah kanan dan kiri dalem (Tisnawati \& Natalia, 2017). Tiga pintu tersebut juga terlihat pada akses masuk pada Ruang Liwan Masjid Gedhe Mataram Kotagede.

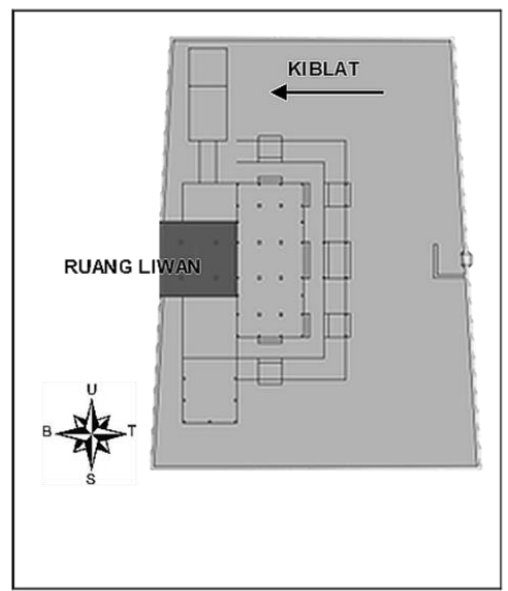

Gambar 6. Arah Hadap Mihrab Ruang Liwan Masjid Mataram Kotagede

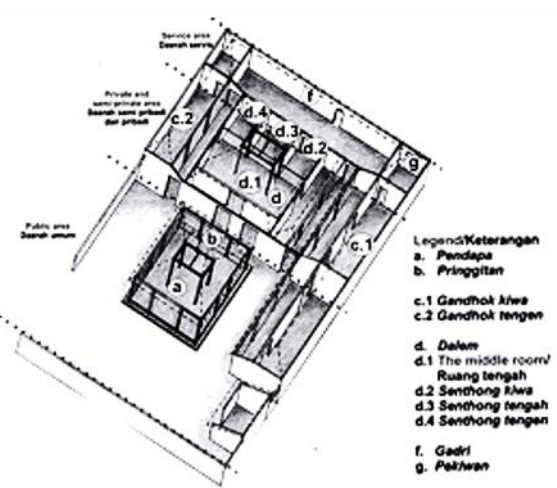

Gambar 7. Pembagian Rumah Tradisional Jawa Sumber: Tisnawati \& Na talia, 2017 
Masjid Gedhe Mataram Kotagede memiliki Ruang Liwan dengan dinding 2 (dua) batu sebagai struktur penyangga atap lambang gantung. Pada dinding Ruang Liwan sebelah timur terdapat 3 (tiga) pintu tarung kayu jati masing-masing berukuran $1,8 \times 1,8 \mathrm{~m}^{2}$ yang menghubungkan dengan area serambi di bagian timur (Gambar 8). Pintu memiliki palang kayu dan engsel dari plat besi serta paku besi berbentuk paku keling (Setyowati, Hardiman, \& Murtini, 2017).

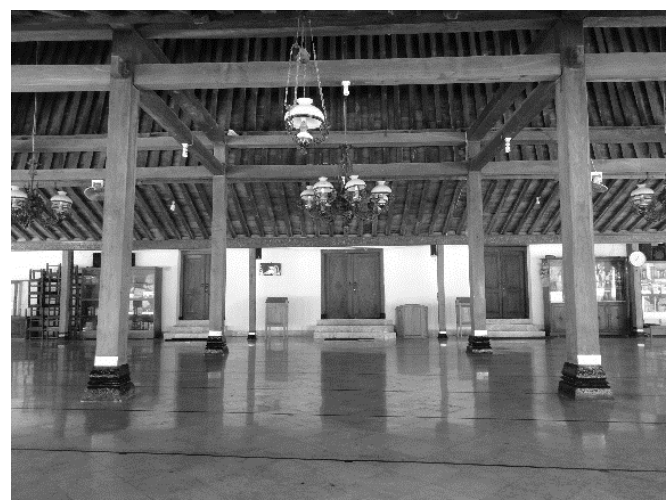

Gambar 8. Tiga Pintu Tarung Ruang Liwan Ma sjid Gedhe Mataram Kotagede

Pada pintu tarung utama yang terletak di tengah di antara ketiga pintu tersebut terdapat ornamen-ornamen yang sarat makna dan merupakan salah satu wujud akulturasi Islam dan Budaya Jawa yang paling menonjol yaitu ornamen dengan tulisan aksara Jawa dan diapit oleh 2 (dua) tulisan Arab (Gambar 9). Selain itu pintu tarung utama ini juga memiliki ornamen wajikan dimana menurut Merbot pada penelitian Dorno (2014) mengatakan bahwa wajikan adalah simbol empat arah mata angin menggambarkan keeratan hubungan antara sesama muslim di seluruh penjuru dunia.

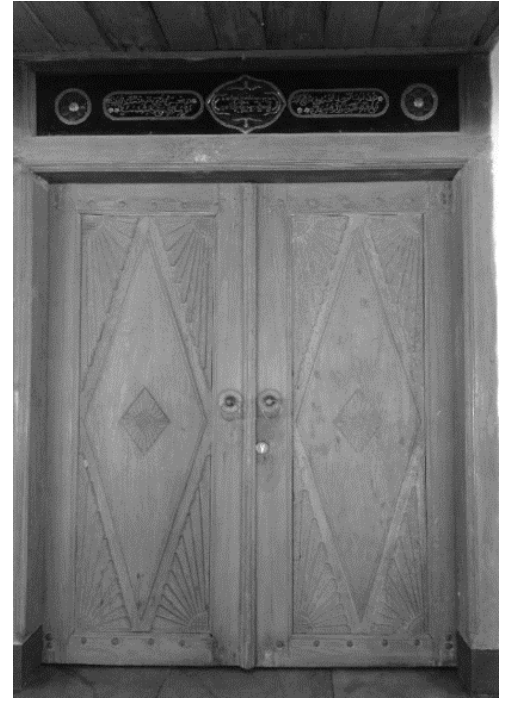

Gambar 9. Ornamen Huruf Jawa dan Arab di Atas Pintu Uta ma Ruang Liwan Masjid Gedhe Mataram Kotagede

Ornamen dengan aksara Jawa berbunyi "Kamulyaaken Tahun Ehe, Hangademaken Cipto Swaraning Jalmi" yang artinya "Kemuliaan Tahun Ehe, Mendinginkan Kalbu Suara Hati Manusia" (Gambar 10). Sedangkan ornamen berupa susunan huruf Arab di sebelah kiri berbunyi "Hijrotunnabiyyi Muhammadin SAW min makkati ila madinati, Alfu wa sittani arba'u wa tsaminuuna sanatin" yang artinya "Hijrahnya Nabi Muhammad dari Makkah ke Madinah, 1684 tahun" (Gambar 11) dan ornamen sebelah kanan yang berbunyi "Hadzal Babal Masjidil-Harom Fillah Irtajul-Akbar, Tabi'al-Baladil Akbar Surakarta Adiningrat" artinya "Ini adalah pintu Masjidil Haram, di dalam keridhoan Allah mengharap kebesaranNya, mengikuti negara besar 'Surakarta" (Gambar 12) (hasil wawancara dengan Bp. Ramang, 2020).

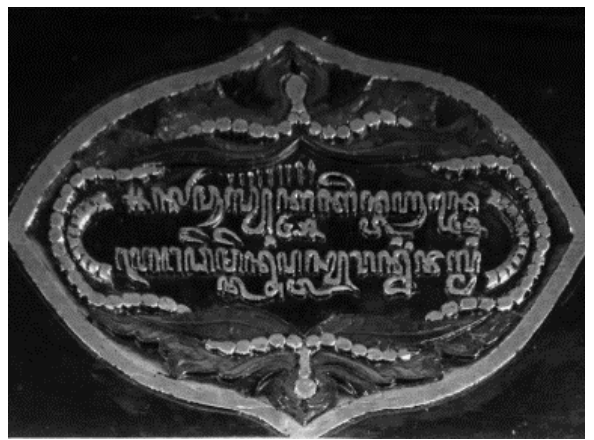

Gambar 10. Ornamen Tulisan Aksara Jawa di Atas Pintu Uta ma Ruang Liwan Masjid Gedhe Mataram Kotagede 


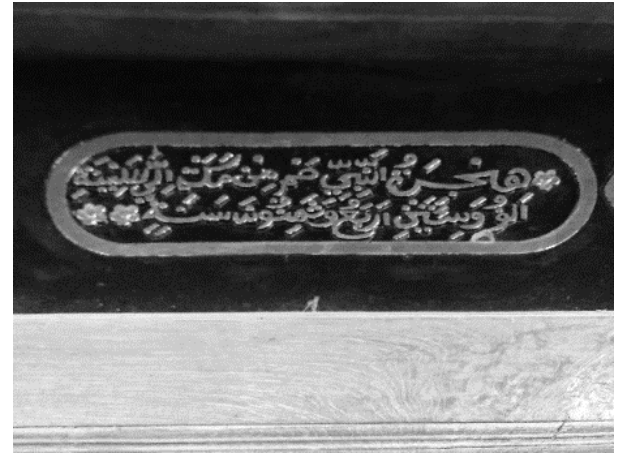

Gambar 11. Ornamen Tulisan Huruf Arab Sebelah Kiri di Atas Pintu Utama Ruang Liwan Masjid Gedhe Mataram Kotagede

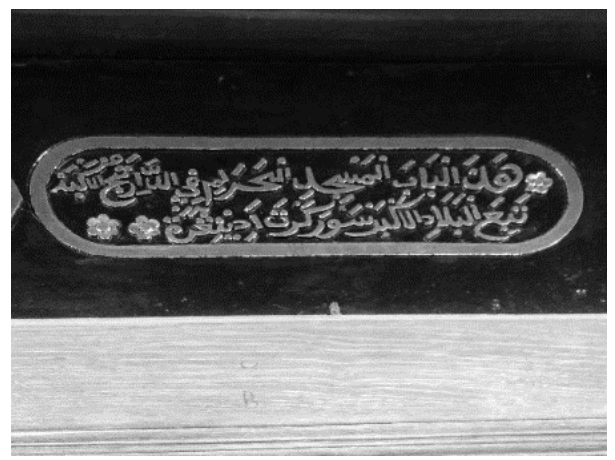

Gambar 12. Ornamen Tulisan Huruf Arab Sebelah Kanan di Atas Pintu Utama Ruang Liwan Masjid Gedhe Mataram Kotagede

Wujud ornamen tersebut merupakan sebuah simbol perwujudan akulturasi Islam dan Jawa yang menyimpan kunci dari makna nilai hakiki pendirian Masjid Gedhe Mataram Kotagede tersebut. Masjid ini ada di bawah naungan negara besar 'Surakarta' pada masa itu. Tulisan mengenai hijrah Nabi Muhammad SAW pada ornamen menandai sebuah peristiwa dimana masjid Gedhe Mataram Kotagede ini dilakukan perluasan yang selesai pada tahun 1864 sejak masa Hijrah Nabi Muhammad SAW (hasil wawancara dengan Bp. Ramang, 2020). Pintu tarung utama pada Masjid Gedhe Mataram Kotagede sendiri merupakan sebuah simbolisasi dari apa yang ingin diungkapkan dalam tulisan tersebut. Pintu tersebut dianggap sebagai pintu Masjidil Haram dimana Masjidil Haram merupakan tempat tersuci bagi umat muslim karena masjid ini terletak mengelilingi $K a$ 'bah. Keberadaan pintu masuk utama ini diharapkan menjadi simbol sebuah gerbang masuk ke dalam masjid untuk menjernihkan kalbu dan suara hati sebagai seorang hamba bagi siapapun yang masuk masjid. Di sisi lain juga dapat diartikan bahwa tahun pendirian Masjid Gedhe Mataram Kotagede pada Tahun Ehe (Tahun Kalender Jawa) ini menjadi tahun kemuliaan yang menjadi tanda terlahirnya sebuah masjid yang dapat mendinginkan dan mengendapkan kalbu suara hati manusia. Keberadaan pintu tarung utama beserta ornamen ini menunjukkan bagaimana makna secara Islam yang disimbolkan dalam sebuah karya arsitektur dilengkapi dengan penghayatan nilai filosofis yang diyakini masyarakat Jawa mengenai hubungan vertikal dengan Tuhan dan horisontal dengan sesama umat muslim. Selain itu, tatanan pada masjid Gedhe Mataram Kotagede ini juga mengikuti tatanan seperti halnya di Masjidil Haram (hasil wawancara dengan Bp. Ramang, 2020).

Memasuki area dalam Ruang Liwan, hal yang tampak pada ruangan ini adalah terdapat Saka Guru di bagian tengah ruangan (Gambar 13). Ruang Liwan pada Masjid Gedhe Mataram Kotagede memiliki 4 (empat) tiang utama (Saka Guru) dengan dimesi kolom 0,3 x 0,3 $\mathrm{m}^{2}$ dan tinggi $5 \mathrm{~m}$ yang mendukung struktur atap tajug lambang gantung (Setyowati, Hardiman, \& Murtini, 2017). Secara aspek tipologi, tradisionalitas wujud dasar arsitektur masjid memiliki bentuk-bentuk denah persegi/bujursangkar sebagai bagian utama masjid yang dilengkapi dengan 4 kolom penyangga (saka guru) seperti yang terdapat pada Masjid Agung Demak (Kusyanto, 2020). Saka guru dianggap sebagai perlambang dari 4 (empat) unsur dalam pandangan masyarakat Jawa yaitu tanah, air, api, dan udara dimana empat unsur tersebut dipercaya akan memperkuat rumah baik secara fisik dan mental penghuninya (Ronald, 2005). Disamping melambangkan keempat unsur alam yang penting tersebut, saka guru diyakini berkaitan juga dengan arah mata angin yang melambangkan empat arah mata angin utama, yaitu utara, timur, selatan, dan barat. Konsepsi keempat arah mata angin dengan satu titik pusat di tengahnya merupakan lambang kedudukan manusia Jawa yang mendudukkan dirinya sebagai bagian dari yang Absolut (kekuasaan Tuhan) dan absolut bagi dirinya sendiri (Ronald, 2005). 


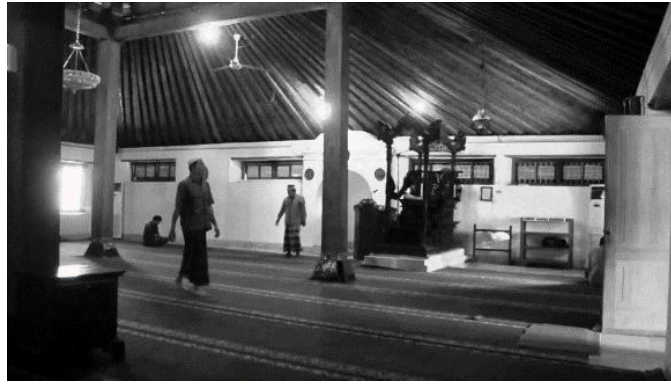

Gambar 13. Saka Guru pada Ruang Liwan Masjid Gedhe Mataram Kotagede

Sumber:https:/grcfarraz.com/motif-motifornamen/, diunduh pada 12 Juni2020, 18:55

Konsepsi saka guru sering diidentikkan dengan konsepsi mancapat, yaitu konsepsi empat arah mata angin yang memperhitungkan arah mata angin tengah di antara keempat arah mata angin tadi. Tiap arah angin selain berkaitan dengan konsepsi dewa, juga berkaitan dengan warna dasar. Padanan keempat arah tadi menggambarkan warna seperti timur serupa dengan warna putih, selatan serupa dengan warna merah, barat serupa warna kuning, utara serupa warna hitam, sedangkan pusat merupakan sintesis dari keempat arah mata angin tersebut serupa pancawarna. Perlambang keempat arah mata angin tadi, diperluas oleh agama Islam dengan memberinya makna moral dalam kehidupan sehari-hari. Makna moral tersebut dilambangkan sebagai berikut: putih identik dengan ketenangan batin yang diujudkan dalam napsu mutmainah. Merah identik dengan marah yang melambangkan napsu amarah. Kuning menggambarkan keinginan atau napsu supiah dan hitam melambangkan warna kecemburuan atau napsu aluamah (Lombard, 2000).

Mihrab yang terdapat pada Ruang Liwan memiliki ornamen motif sulur daun dan tiang semu dengan bingkai di bagian atasnya (Gambar 14). Hal ini sesuai dengan ciri dari arsitektur Islam yaitu masjid yang melarang ornamen yang menyerupai figur manusia dan hewan. Di dalam Ruang Liwan juga terdapat sebuah mimbar yang terbuat dari ukiran kayu jati. Mimbar juga merupakan salah satu ciri dari arsitektur Islam (Setyowati, Hardiman, \& Murtini, 2017). Secara keseluruhan interior Ruang Liwan Masjid Gedhe Mataram Kotagede didominasi oleh warna alami kayu (berasal dari material kayu Jati), yang diketahui menjadi salah satu ciri khas dari masjid-masjid Jawa pada masa Kerajaan Mataram Islam.

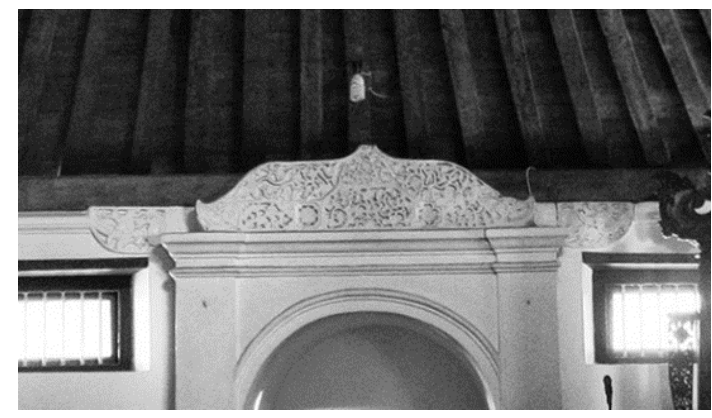

Gambar 14. Mihrab Ruang Liwan Masjid Gedhe Mataram Kotagede

Sumber: Dok. Penulis, 2020

Kelompok motif hias tumbuh-tumbuhan yang terdapat pada Ruang Liwan khususnya pada Mihrab umumnya bermakna suci dan indah, ukirannya halus dan simetris dan mengandung daya estetis (Ismunandar, 1990). Ragam hias tumbuh-tumbuhan yang paling banyak dijumpai adalah ragam hias dalam bentuk pohon merambat atau sering disebut dengan istilah ragam hias sulur-suluran atau lunglungan (Gambar 15). Pada masa Hindu-Budha, motif lung-lungan ini secara simbolik memiliki makna sebagai tumbuhan surga, sedangkan dalam Islam, motif lung-lungan pada bangunan masjid bermakna pengingat bagi kaum muslimin untuk memiliki jiwa sosial yang tinggi berupa sikap tolong-menolong (Pradana, 2020). Ragam hias tumbuhan merambat dimaksudkan untuk melambangkan kedamaian, pertumbuhan dan atau kesuburan (Hamzuri, 2000). Lung-lungan yang selalu dibuat meliukliuk ke atas, bawah, kanan, dan kiri dimaksudkan sebagai perlambang bahwa hendaknya manusia ketika hidup di dalam masyarakat selalu ingat terhadap yang menciptakan yaitu Tuhan dan berbuat baik ketika hidup di dalam masyarakat. motif lunglungan yang sering diidentikkan dengan bunga yang selalu memancarkan bau harum dipakai sebagai simbol cinta kasih, yaitu cinta kasih kepada sesamanya, cinta kasih dengan lingkungan, dan cinta kasih dengan Tuhannya. Dengan berbekal cinta kasih tersebut diharapkan dapat tercapainya kedamaian dan keselarasan hidup yang pada ujungnya manusia dapat hidup dengan tenang, aman, tentram, damai dan penuh kasih sayang. 


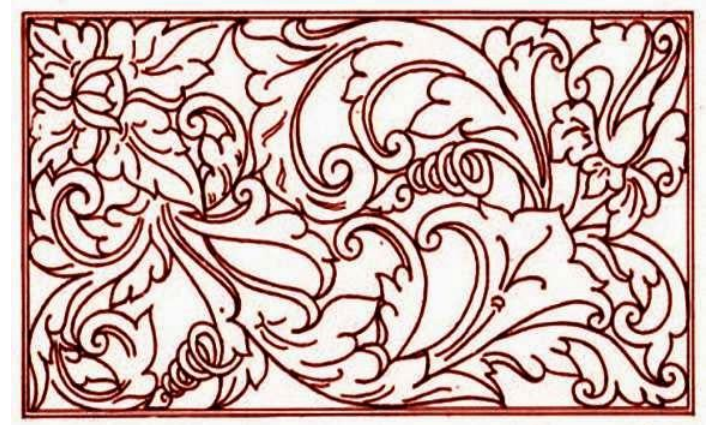

Gambar 15. Motif Sulur-suluran Mihrab Ruang Liwan Masjid Mataram Kotagede Sumber: https://grcfarraz.com/motif-motiforna men/, diunduh pada 12 Juni2020, 17:20

\section{KESIMPULAN}

Hasil pembahasan di atas memberikan satu kesimpulan bahwa lahirnya karya arsitektur yang memuat nilai-nilai Islami dapat berjalan beriringan dengan budaya Jawa. Arsitektur Islam tidak dibatasi oleh budaya negara atau wilayah manapun karena keragaman tempat tersebut justru membawa ciri tersendiri bagi Arsitektur Islam. Arsitektur Islam mempunyai bahasa arsitektur yang berbeda tergantung lokasi dan fungsi dari bangunan itu sendiri. Situasi politik, budaya, dan kepercayaan turut membentuk sebuah karya bangunan arsitektur terutama sebuah masjid sebagai suatu sarana dakwah.

Pada Ruang Liwan Masjid Gedhe Mataram Kotagede ini terbukti terdapat akulturasi Islam dan budaya Jawa yang berjalan secara harmonis membentuk gaya khas arsitektur Masjid Agung pada masa Kerajaan Mataram Islam dimana gaya arsitektur tersebut mengandung nilai kosmologi Jawa yang telah diyakini dan diterapkan masyarakat Jawa dalam keseharian diperluas dengan pandangan mengenai nilai Islami. Kekhasan tersebut terdapat pada elemen-elemen arsitektural di dalam Ruang Liwan Masjid Gedhe Mataram Kotagede berupa Saka Guru, material-material alami kayu, serta ornamen-ornamen yang dapat dipahami menjadi satu kesatuan akan sebuah akulturasi antara filosofi yang terkandung dalam nilai budaya Jawa disandingkan dengan nilai-nilai ajaran Islam yang berjalan selaras dan berdampingan namun menuju satu makna tujuan yang satu yaitu tentang hakikat untuk tunduk kepada kekuasaan terbesar yaitu kekuasaan Tuhan. Akulturasi semacam ini selain membentuk corak baru yang khas pada Ruang Liwan di Masjid Jawa, juga memperkaya makna dalam penyampaian nilai Islam pada masyarakat Jawa itu sendiri.

\section{REFERENSI}

Akromusyuhada, A. (2019, Mei). Penerapan Konsep Islam Pada Sarana dan Prasarana Pendidikan: Tinjauan Peraturan Menteri Pendidikan Nasional Republik Indonesia Nomor 24 Tahun 2007 Tentang Standar Sarana dan Prasarana Untuk SD/MI, SMP/MTs, dan SMA/MA. Jurnal Tahdzibi: Manajemen Pendidikan Islam, 4 No. 1. doi:10.24853/tahdzibi.4.1.41-48

Aziz, D. K. (2013, Juli-Desember). Akulturasi Islam dan Budaya Jawa. Fikrah, I No. 2, 253-286.

Bakhrodin, Istiqomah, U., \& Abdullah, A. A. (2019, Oktober). Identifikasi Etnomatematika Pada Masjid Mataram Kotagede Yogyakarta. Jurnal Ilmiah Edukasi Matematika Soulmath, 7 (2), 113-124.

doi:http://dx.doi.org/10.25139/smj.v7i 2.1921

Behrend, T. E. (1989). Kraton and Cosmos in Traditional Java. In: Archipel, volume 37, 1989. Villes d'Insulinde (II) $\mathrm{pp}$. 173-187; doi: 10.3406/arch.1989.2569 http://www.persee.fr/doc/arch_00448613_1989_num_37_1_2569

Cahyandari, G. O. (2012). Tata Ruang dan Elemen Arsitektur pada Rumah Jawa di Yogyakarta. Jurnal Arsitektur Komposisi, 10 Nomor 2, 105-111.

Dorno, J. (2014). Bentuk dan Makna Simbolik Ornamen Ukir Pada Interior Masjid Gedhe Yogyakarta. Skripsi, Universitas Negeri Yogyakarta, Yogyakarta.

Fitri, A. Z. (2012). Pola Interaksi Harmonis Antara Mitos, Sakral, dan Kearifan Lokal Masyarakat Pasuruan. El Harakah, 14 No. 1.

Hamzuri. (2000). Warisan Tradisional Itu Indah dan Unik. Jakarta: Direktorat Jenderal Kebudayaan.

Handoko, W. (2014). Tradisi Nisan Menhir Pada Makam Kuno Raja-Raja di 
Wilayah Kerajaan Hitu. Kapata Arkeologi, 10(1), 33-46.

Ismunandar, R. (1990). Joglo: Arsitektur Rumah Tradisional Jawa. Semarang: Dahara Prize.

Koentjaraningrat. (2009). Pengantar Ilmu Antropologi. Jakarta: Rineka Cipta.

Kresna, A. A. (2013, September). Demokrasi dan Kekuasaan Dalam Pandangan Hidup Orang Jawa. Jurnal Ultima Humaniora, I Nomor 2.

Kusyanto, M. (2020). Kearifan Lokal Arsitektur Masjid Demakan. EE Conference Series 03 TALENTA Conference Series p-ISSN: 2654-7031, e-ISSN: 2654-704X, DOI: 10.32734/ee.v3i1.854

https://talentaconfseries.usu.ac.id/ee

Latief, H. (2013). Menelaah Gerakan Modernis-Reformis Islam Melalui Kota Gede: Pembacaan Seorang Antroplog Jepang. Studia Islamika, 20 No. 2, 377 .

Lombard, D. (2000). Nusa Jawa: Silang Budaya: Kajian Sejarah Terpadu. Jakarta: Gramedia Pustaka Utama.

Maryono, M. M. (2016, Januari-Juni). Menyibak Keistimewaan Manajemen Masjid. Jurnal MD.

Muqoyyidin, A. W. (2012). Dialektika Islam dan Budaya Lokal Dalam Bidang Sosial Sebagai Salah Satu Wajah Islam Jawa. El-Harakah, 14 No. 1, 18-33.

Ngationo, A. (2018). Peranan Raden Patah Dalam Mengembangkan Kerajaan Demak Pada Tahun 1478-1518. Kalpataru, 4 Nomor 1, 17-28.

Pradana, R. W. (2020, April). Bentuk dan Makna Simbolik Ragam Hias Pada Masjid Sunan Giri. SPACE, 7 No. 1.

Prasetyo, J. E. (2016). Masjid Pathok Negoro Plosokuning 1724-2014 (Kajian Arsitektur Jawa). Jakarta: UIN Syarif Hidayatullah.

Ramadhana, D., \& Dharoko, A. (2015, Mei). Ruang Sakral Dan Profan Dalam Arsitektur Masjid Agung Demak, Jawa Tengah. INERSIA, XIV No. 1, 13-25.

Ronald, A. (2005). Nilai-Nilai Arsitektur Rumah Tradisional Jawa. Yogyakarta: Gadjah Mada University Press.
Roszi, J. P. (2018). Akulturasi Nilai-Nilai Budaya Lokal dan Keagamaan dan Pengaruhnya Terhadap Perilaku Sosial. FOKUS: Jurnal Kajian KeIslaman dan Kemasyarakatan, 3 No. 2. Retrieved from

http://journal.staincurup.ac.id/index.ph $\mathrm{p} / \mathrm{JF}$

Santoso, I., Setioko, B., \& Pendelaki, E. E. (2015). Pengaruh Tanda-Tanda Kosmologis Kota Jawa Pada Masjid Demak Perwujudan Visual Yang BerKearifan Lokal. Seminar Nasional "Menuju Arsitektur dan Ruang Perkotaan Yang Ber-Kearifan Lokal". PDTAP.

Setyowati, E., Hardiman, G., \& Murtini, T. W. (2017). Akulturasi Budaya pada Bangunan Masjid Gedhe Mataram Yogyakarta. Seminar Ikatan Peneliti Lingkungan Binaan Indonesia (IPLBI) 1 (pp. A011-018). Sekolah Tinggi Teknologi Cirebon, Universitas Indraprasta, Universitas Trisakti. doi:https://doi.org/10.32315/sem1.a01 1

Soemardjan, S. (1962). Social Change in Djokjakarta. Ithaca, New York.

Suratno. (2003). Tata Kota Tradisional Jawa Sebagai Penunjang Pariwisata Di Kotagede Yogyakarta (Tinjauan Estetis) Jurnal Masyarakat dan Budaya, Volume 5 No. 1.

Syamsiah, N. R. (2018, Januari). Kajian Perbandingan Gaya Arsitektur Dan Pola Ruang Masjid Agung Surakarta Dan Masjid Gedhe Kauman Yogyakarta. SINEKTIKA Jurnal Arsitektur, 15 No. 1, 1-6. Retrieved from

http://journals.ums.ac.id/index.php/sin ektika

Tisnawati, E., \& Natalia, D. A. (2017). Tipologi Masjid Kagungan Dalem di Imogiri. Prosiding Seminar Heritage. A 075. IPLBI.

Umar. (n.d.). Integrasi Konsep Islami Dan Konsep Arsitektur Modern Pada Perancangan Arsitektur Masjid. Radial Jurnal Peradaban Sains.

Utami, Thonthowi, I., Wahyuni, S., \& Nulhakim, L. (2013, Agustus). 
Penerapan Konsep Islam Pada

Perancangan Masjid Salman ITB

Bandung. Jurnal Reka Karsa: Jurnal

Istitut Teknologi Nasional, Teknik

Arsitektur Itenas, 01 No. 02, 3.

Zaki, M. (2017). Kearifan Lokal Jawa Pada

Wujud Bentuk Dan Ruang Arsitektur Masjid Tradisional Jawa (Studi Kasus: Masjid Agung Demak). Master's Thesis, Undip. 